\title{
Tension and Ampacity Monitoring System for Overhead Lines
}

\author{
Igor Albizu, Member, IEEE, Elvira Fernandez, Member, IEEE, Pablo Eguia, Member, IEEE, Esther Torres and Angel
} Javier Mazon, Member, IEEE

\begin{abstract}
Real time monitoring allows the determination of the line state and the calculation of the actual rating value. The real time monitoring systems measure sag, conductor tension, conductor temperature or weather related magnitudes. In this paper, a new ampacity monitoring system for overhead lines, based on the conductor tension, the ambient temperature, the solar radiation and the current intensity, is presented. The measurements are transmitted via GPRS to a control center where a software program calculates the ampacity value. The system takes into account the creep deformation experienced by the conductors during their lifetime and calibrates the tensiontemperature reference and the maximum allowable temperature in order to obtain the ampacity. The system includes both hardware implementation and remote control software.
\end{abstract}

Index Terms - ampacity, overhead lines, rating, real time monitoring.

\section{NOMENCLATURE}

$T$

tension

$D \quad$ sag

$\theta_{\text {con }}$ conductor temperature

$\theta_{\text {amb }}$ ambient temperature

$S \quad$ solar radiation

I current intensity

$V \quad$ wind speed

$L \quad$ length

$A$ area

$E \quad$ elastic modulus

$\alpha \quad$ coefficient of thermal expansion

$\sigma \quad$ stress

$\varepsilon \quad$ total strain

$\varepsilon^{\theta} \quad$ strain related to temperature

$\varepsilon^{T} \quad$ strain related to tension

$\varepsilon^{\text {creep }} \quad$ strain related to creep

$\varepsilon^{\mathrm{mc}} \quad$ strain related to metallurgical creep

$\varepsilon^{\mathrm{gs}} \quad$ strain related to geometrical settlement

$s \quad$ span length

$t$ time

g related to catenary geometry

con related to conductor

core related to core

a

\author{
o related to reference condition \\ $P_{j} \quad$ Joule heating \\ $P_{m} \quad$ magnetic heating \\ $P_{S} \quad$ solar heating \\ $P_{c} \quad$ convective cooling \\ $P_{r} \quad$ radiative cooling
}

\section{INTRODUCTION}

$\mathrm{T}$ HE power transmitted in both transmission and distribution electrical lines has increased considerably over the past twenty years. As a result of the increased power flow, some lines can be close to their ampacity limit. The ampacity or thermal rating is that current which will meet the design, security and safety criteria of a particular line. Therefore, there is great pressure to increase the power flow in existing right of ways using existing infrastructure as far as possible. Traditionally, the upgrading of the line has been used in order to increase the line rating. The main drawback of these methods is the need to strengthen the towers. For this reason, methods without the need to strengthen the towers that allow increasing the line power flow securely and safely, close to its ampacity limit, have been developed. Among these methods, real time monitoring can be found.

Real time monitoring allows the determination of the line state and the calculation of the actual ampacity value [1-2] Making a thermal calculation [3-4], the ampacity is calculated as the current intensity value that makes the conductor reach the maximum allowable temperature. There are monitoring systems that measure weather related magnitudes [5-6], the conductor temperature [7-10], the conductor tension [11-12] or the sag [13-14].

One aspect to consider by the real time monitoring systems is the effect of the creep, which is the permanent deformation of the conductor. The result is a loosening of the conductor. Therefore, for a given temperature of the conductor, the corresponding value of the tension is reduced over time. As a consequence, the maximum allowable temperature related to the sag limit is reduced and the ampacity is reduced too.

In this paper, a new ampacity monitoring system that besides having the benefits of some of the existing monitoring systems, takes into account the creep deformation experienced by the conductors during their lifetime is presented. The creep is evaluated updating the conductor tension and temperature reference.

\section{TAM SYSTEM}

From the analysis of the existing systems, the authors have designed an ampacity monitoring system that besides presenting the benefits of some of the methods analyzed, takes into account the creep deformation experienced by the
This work was supported by the Bizkaiko Foru Aldundia-Diputacion de Bizkaia and the University of the Basque Country UPV/EHU under (DPI2009-08454), the UPV/EHU (UFI 11/28), and the Eusko Jaurlaritzako Hezkuntza, Unibertsitate eta Ikerketa Saila (Euskal unibertsitate-sistemako ikerketa-taldeak Ref. IT532-10).

I. Albizu, E. Fernández, P. Eguía, E. Torres and A. J. Mazón, are with the Department of Electrical Engineering, Faculty of Engineering of Bilbao, University of the Basque Country UPV/EHU, Bilbao 48013, Spain (e-mail igor.albizu@ehu.es,_elvira.fernandezh@ehu.es,_pablo.eguia@ehu.es, esther.torresi@ehu.es, javier.mazon@ehu.es ). 
conductors during their lifetime. The system has been developed seeking simplicity (low cost), reliability and accuracy in the calculated ampacity value.

The monitoring system is based on an ampacity characterization methodology that considers only the monitoring of the mechanical tension, the ambient temperature, the solar radiation and the current intensity. From these values, a formulation has been developed that estimates the conductor creep deformation, the maximum allowable temperature, the conductor temperature, the wind speed, and finally the line ampacity. The system developed has been called TAM System (Tension \& Ampacity Monitoring System).

\section{A. Calculation processes}

The developed system carries out two calculation processes that run in parallel: the calibration process and the process of ampacity calculation.

\section{1) Calibration process}

The calibration relates the value of the conductor tension to the value of the conductor temperature. The tension $T$ is measured directly. However, the temperature of the conductor $\theta_{c o n}$ must be estimated. The estimate of the conductor temperature is based on the tension $T$, the ambient temperature $\theta_{a m b}$, the solar radiation $S$ and the current intensity $I$. From the measured tension and the calculated temperature of the conductor, the tension-temperature reference $T-\theta_{c o n}$ is obtained. Once the calibration is carried out, the creep deformation and the maximum allowable temperature values are updated (Fig. 1).

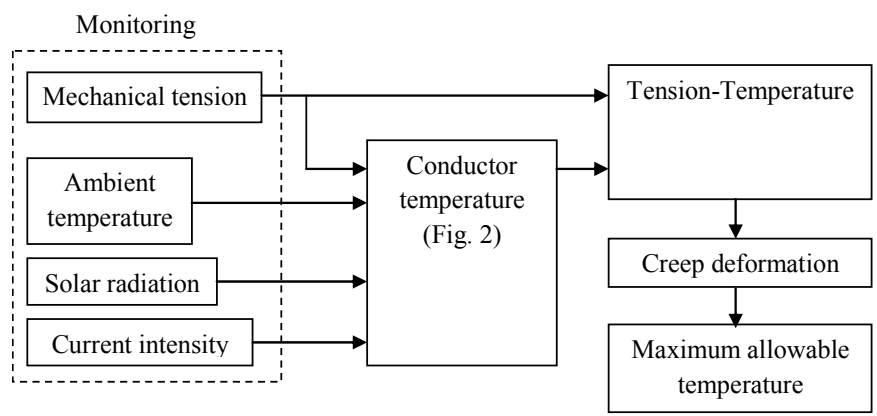

Fig 1. Calibration process

The conductor temperature is calculated making a thermal calculation (Fig. 2). To ensure a correct estimate of the conductor temperature $\theta_{\text {con }}$, it is not based on instantaneous values but on average values corresponding to a certain period of time $t_{\text {calibration. }}$. The number $n$ of measurements taken for the mean and the deviation calculation is a function of the sampling period $t_{\text {sampling }}(1)$. In addition, to ensure that the conditions during this period are steady and the temperature and the tension have no significant variations, the tension standard deviation during the period is calculated $(2,3)$. The deviation $\sigma_{T, j}$ that corresponds to the measurement $j$ is calculated from the last $n$ measurements. The period is considered steady if the deviation is below a certain threshold

\section{$\sigma_{T, \text { threshold }}$.}

The wind speed $V$ needed for the thermal calculation is not measured and it is unknown. Therefore the wind speed value is assumed. The difference between the assumed value and the actual value results in an error in the calculated conductor temperature. The results obtained from a pilot installation show that with a long period of calibration $t_{\text {calibration }}$ (e.g. 1 hour) and a low tension deviation threshold $\sigma_{T, \text { threshold }}$ (i.e. low tension variation), the wind speed in the period is low (below $1 \mathrm{~m} / \mathrm{s}$ ). As a result, the assumed wind speed value is low (e.g. $0.5 \mathrm{~m} / \mathrm{s}$ ). Another aspect that has been analyzed is the influence of the current intensity value on the conductor temperature error. When the current intensity is low, the error related to the wind speed difference is lower. Hence, the calibration is carried out when the average current intensity $\bar{I}$ is below a threshold value $I_{\text {threshold }}$. As it is shown below, in the system verification sub-section, this methodology guarantees a low difference between the calculated and the measured temperature values. The difference is between 1 and $2{ }^{\circ} \mathrm{C}$.

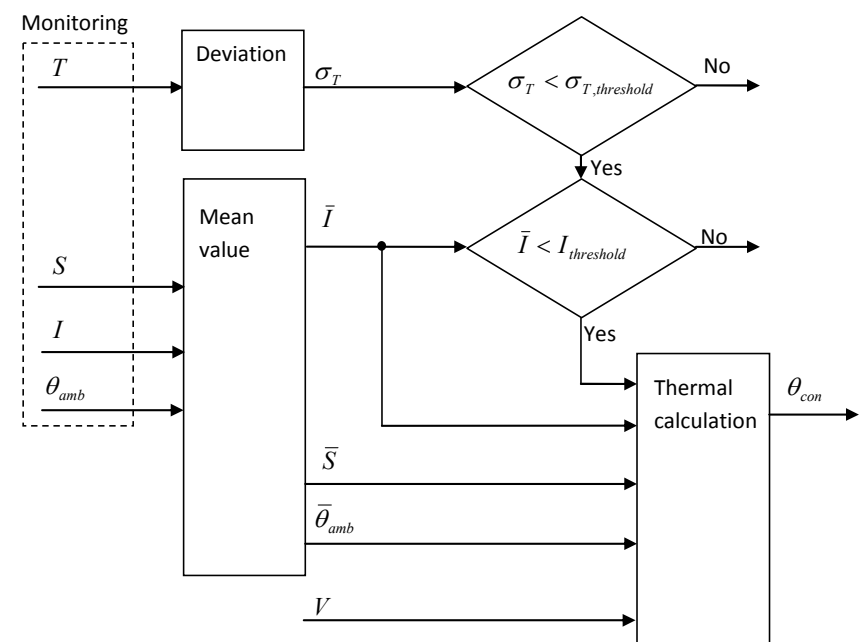

Fig 2. Conductor temperature calculation in the calibration process

$t_{\text {calibration }}=n \cdot t_{\text {sampling }}$

$\bar{T}_{j}=\sum_{i=j-(n-1)}^{j} T_{i} / n$

$\sigma_{T, j}=\sqrt{\sum_{i=j-(n-1)}^{j}\left(T_{i}-\bar{T}_{j}\right)^{2} /(n-1)}$

Once the tension-temperature calibration is obtained, the creep deformation values are updated. This is carried out using a sag-tension method developed by some of the authors [15-17]. This method models the core and the aluminum independently and it is able to model the knee-point temperature where the aluminum gets slack. The method is described in the Appendix.

The creep related to the calibrated tension-temperature $T-\theta_{\text {con }}$ values is calculated iteratively. The creep strain is 
iterated until the tension and the temperature values obtained in the sag-tension calculation are those obtained in the calibration. Firstly, from the tension $T$, the conductor temperature $\theta_{c o n}$, and the core and aluminum creep $\varepsilon_{\text {core }}^{\text {cree }}$ and $\varepsilon_{a}^{\text {creep }}$, the core and aluminum tension values $T_{\text {core }}$ and $T_{a}$ are obtained (4-6). The method models separately the core and aluminum creep, and as a result, there are two unknown values. The problem is solved sharing the developed creep $\Delta \varepsilon^{\text {creep }}$ between the core and the aluminum by some coefficients $k_{\text {core }}$ and $k_{a}$ (7-8). The creep developed by the aluminum is higher than the creep developed by the core. Therefore, a simplification can be to assign all the creep to the aluminum $\left(k_{\text {core }}=0\right.$ and $k_{a}=1$ ). A better approximation can be made with information about the creep behavior of the core and the aluminum of the particular conductor, which is obtained from stress-strain and creep tests. If the aluminum is slack $\left(T_{a}=0\right)$ in the calibrated condition, for example in the case of a gap-type conductor due to the low knee-point temperature, all the creep must be assigned to the core ( $k_{\text {core }}=1$ and $k_{a}=0$ ). Thus, $\Delta \varepsilon^{\text {creep }}$ is iterated until the difference between the conductor length $L_{c o n}$, calculated from the core length $L_{\text {core }}(9)$ and the catenary length $L_{g}(11)$ is below a threshold value.

$$
\begin{aligned}
& T_{a}=\left(T-T^{*}\right) \cdot\left(E_{a} \cdot A_{a}\right) /\left(E_{n} \cdot A_{n}+E_{a} \cdot A_{a}\right) \\
& T^{*}=E_{n} \cdot A_{n} \cdot\left[\left(\alpha_{a}-\alpha_{n}\right) \cdot\left(\theta_{\text {con }}-\theta_{o}\right)+\left(\varepsilon_{a}^{\text {creep }}-\varepsilon_{\text {core }}^{\text {creep }}\right)\right] \\
& T_{n}=T-T_{a} \\
& \varepsilon_{\text {creep }}^{\text {crep }}=\varepsilon_{\text {core } \text { inst }}^{\text {cree }}+\Delta \varepsilon^{\text {creep }} \cdot k_{\text {core }} \\
& \varepsilon_{a}^{\text {creep }}=\varepsilon_{a, \text { inst }}^{\text {crep }}+\Delta \varepsilon^{\text {creep }} \cdot k_{a} \\
& L_{\text {core }}=L_{o}^{\text {core }} \cdot\left(1+\left(T_{n}-T_{n, \text { inst }}\right) /\left(E_{n} \cdot A_{n}\right)+\alpha_{n} \cdot\left(\theta_{\text {con }}-\theta_{o}\right)+\varepsilon_{\text {core }}^{\text {creep }}\right) \\
& c=T / \omega \\
& L_{g}=2 \cdot c \cdot \sinh ((s / 2) / c)
\end{aligned}
$$

Finally, with the new values of the creep deformation $\varepsilon_{\text {core }}^{\text {crep }}$ and $\varepsilon_{a}^{\text {creep }}$, the maximum allowable temperature $\theta_{\max }$ related to the sag limit is updated. The maximum allowable temperature is calculated using the sag-tension calculation method. The conductor temperature is iterated until the sag value given by the calculation is the sag limit value $D_{\max }$ (Fig. 3).

The creep deformation and the maximum allowable temperature values obtained in the calibration process are used in the process of ampacity calculation.

2) Process of ampacity calculation

This process obtains continuously the ampacity value from the tension, the ambient temperature, the solar radiation and the current intensity values (Fig. 4).

The first step is to obtain the temperature of the conductor from the measured tension. The conductor temperature is calculated using the sag-tension method described in the Appendix. The calculation is similar to the calculation of the maximum allowable temperature (Fig. 3). In this case, from the measured tension $T$ and the creep given by the calibration $\varepsilon_{\text {core }}^{\text {creep }}$ and $\varepsilon_{a}^{\text {creep }}$, the conductor temperature $\theta_{\text {con }}$ is iterated until the tension given by the method $T_{c o n}$ is the measured tension value $T$.

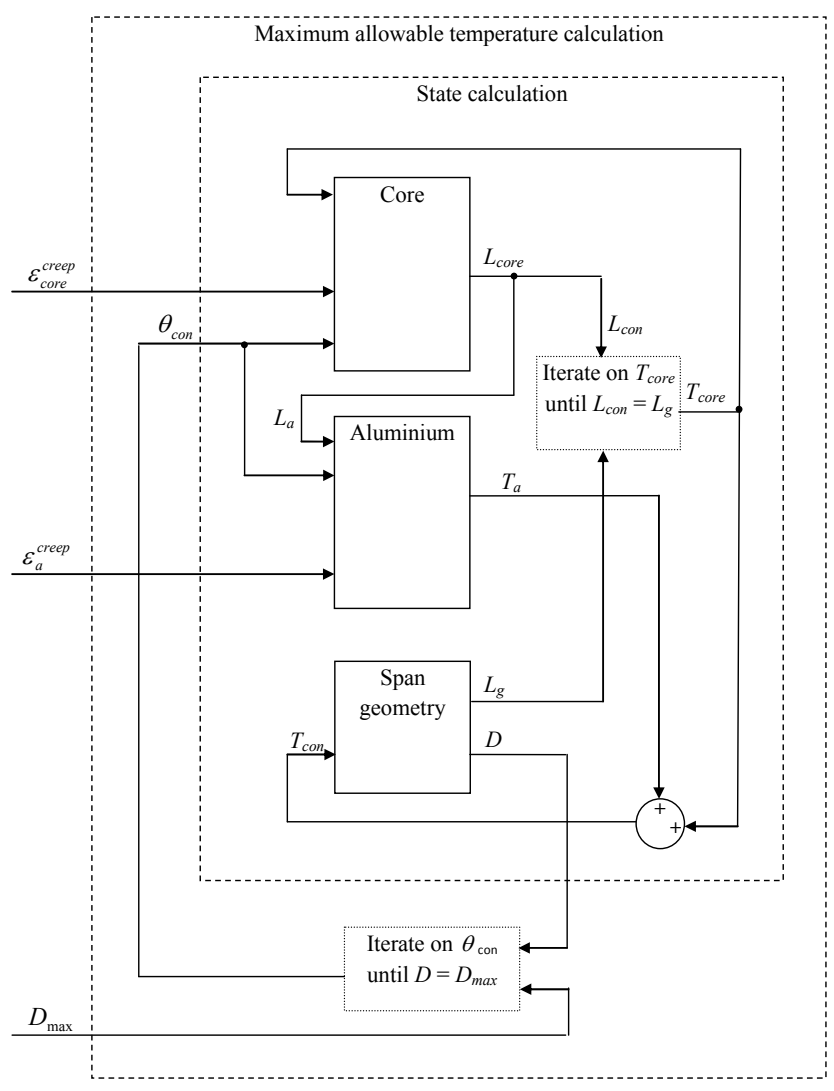

Fig 3. Conductor maximum allowable temperature calculation process

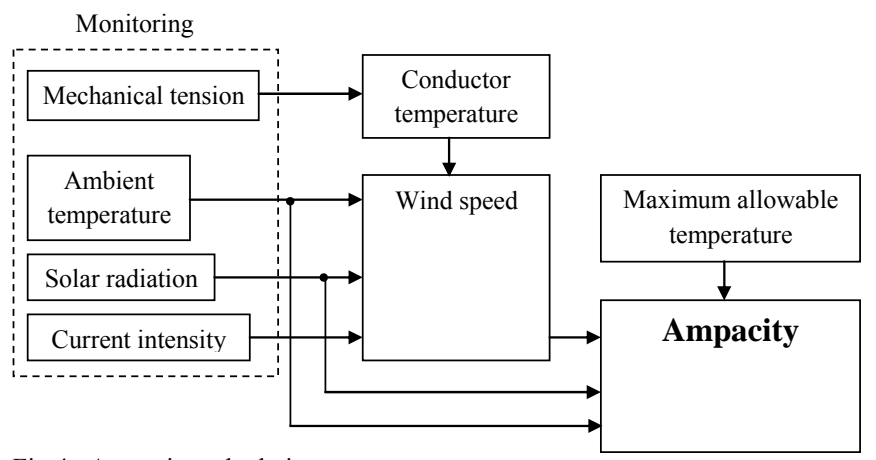

Fig 4. Ampacity calculation process

Then the wind that affects the conductor is calculated. The wind direction is assumed to be perpendicular to the conductor because the cooling effect is all that is required, irrespective of direction. Hence, the calculated wind speed is known as effective wind speed. The wind speed is obtained by a thermal calculation (Appendix). The equations given for the convection cooling calculation have been inverted because they calculate the convection cooling $P_{c}$ from the wind speed $V$. Thus, the value of the convection cooling $P_{c}$ is obtained firstly and then the effective wind speed $V$ is calculated. 
The convective cooling $P_{c}$ is obtained from the Joule heating $P_{j}$, the solar heating $P_{s}$ and the radiative cooling $P_{r}$ (12). The value of the convective cooling $P_{c}$ is compared with the natural convection. If it is lower than the natural convection the wind speed is zero. If it is higher the wind speed is calculated. For this purpose, the equations given by [3] for the convection cooling calculation have been inverted (Fig. 5).

$P_{c}=P_{j}+P_{s}-P_{r}$

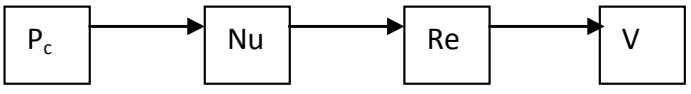

Fig 5. Wind speed calculation process

The Nusselt number $N u$ is obtained from the equation (13) where $\lambda_{\mathrm{f}}$ is the thermal conductivity of air. The Reynolds number $R e$ is obtained from the Nusselt number $N u$ according to equation (14). The values of the coefficients $B_{1}$ and $n$ are obtained from a table. Finally, the wind speed $V$ is obtained from the Reynolds number $R e$ according to equation (15) where $\rho_{\mathrm{r}}$ is the relative air density, $v_{\mathrm{f}}$ is the kinematic viscosity and $D$ is the conductor diameter.

$$
\begin{aligned}
& N u=P_{c} /\left(\pi \cdot \lambda_{f} \cdot\left(\theta_{c o n}-\theta_{a m b}\right)\right) \\
& \operatorname{Re}=\left(N u / B_{1}\right)^{1 / n} \\
& V=\left(\operatorname{Re} \cdot v_{f}\right) /\left(D \cdot \rho_{r}\right)
\end{aligned}
$$

The wind is not measured for different reasons. The main reason is the aim to simplify the system and reduce the cost. Furthermore, although there are wind measuring technologies like the ultrasonic technology that improve the accuracy of the measurement at low speed values, the wind conditions can vary along the line span. For this reason, the calculation of the effective wind speed, which is representative of the conditions along the span, has been chosen.

Finally, the ampacity is calculated from the ambient temperature, the solar radiation, the wind speed and the maximum allowable temperature by a thermal calculation.

The process of the ampacity calculation is carried out continuously because the ampacity value is updated every time new measurements are received.

The uncertainty of the calculated ampacity value is a function of the uncertainty of the variables from which it is calculated. Thus, it is a function of the uncertainty of the measurement of the current intensity, the ambient temperature, the solar radiation and the mechanical tension. It also depends on the uncertainty of the estimate of the conductor temperature and the wind. The analysis carried out has shown that the variables that most affect the ampacity uncertainty are the temperatures [18]. An error in the temperature difference between the conductor temperature and the ambient temperature results in an error of the wind value. The error in the wind speed translates into an error in the ampacity. When the difference between the conductor temperature and the ambient temperature is low the influence of the temperature error in the ampacity calculation is higher and vice versa.
Figure 6 shows an example of the ampacity error as a function of the temperature difference error for some temperature difference values. The conductor of the example is an ACSR Hawk and the maximum allowable temperature is $80^{\circ} \mathrm{C}$. The weather conditions are a wind speed of $0.6 \mathrm{~m} / \mathrm{s}$, an ambient temperature of $25^{\circ} \mathrm{C}$ and a solar radiation of $1000 \mathrm{~W} / \mathrm{m}^{2}$.

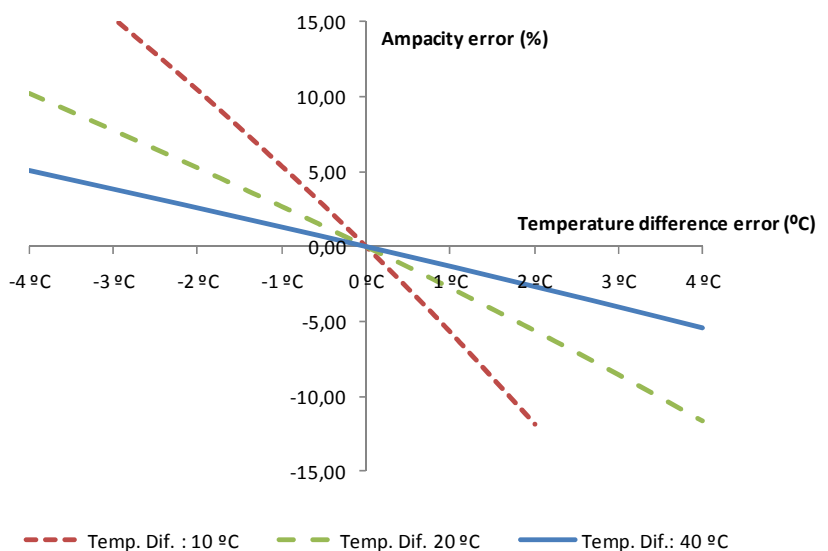

Fig. 6. Ampacity error as a function of the temperature difference error and the temperature difference

When the current intensity increases, the temperature difference increases and as a consequence, the ampacity error decreases. This is shown in Figure 7 for a temperature difference error of $2{ }^{\circ} \mathrm{C}$. The current intensity is given as a percentage of the ampacity. Therefore, the confidence of the estimate increases as the load approaches its ampacity limit.

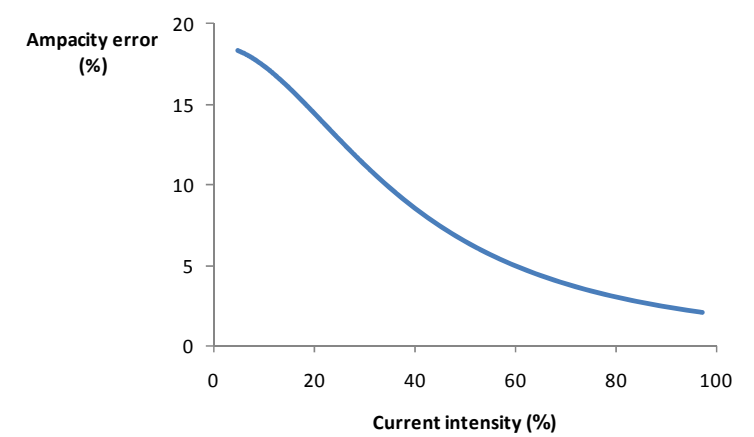

Fig. 7. Ampacity error as a function of the current intensity

\section{B. System Verification}

In order to verify the developed monitoring system, a span of a $30 \mathrm{kV}$ distribution line with a HTLS conductor that the utility Iberdrola was testing [19] has been monitored with the TAM system for two months. The span length is $143.5 \mathrm{~m}$. The load cell was already installed and the solar radiation, the ambient temperature and the current intensity measuring systems have been added to complete the TAM System. In order to verify the TAM System, a conductor temperature measuring system and an anemometer have been used. These elements were already installed for the testing of the conductor. The temperature measuring system is the system known as SMT [9]. The temperature measuring system is installed in the same span where the load cell is installed but it is not located in the same phase. The reason is that for the 
conductor testing, two temperature measuring elements were installed in the adjacent phases not to interfere with the conductor whose tension was measured.

The anemometer measures the wind speed and direction. The direction of the calculated effective wind speed is perpendicular to the conductor. Hence, in order to compare the calculated and the measured wind speeds, the measured values are modified. The wind speed that with a perpendicular direction results in the same cooling than that given by the measured speed and direction values is calculated.

\section{1) Calibration process}

Assuming a wind speed value, $V$, of $0.5 \mathrm{~m} / \mathrm{s}$ and choosing as the threshold values $2 \mathrm{~kg}$ for the tension deviation threshold, $\sigma_{T, \text { threshold }}$, and $100 \mathrm{~A}$ for the current intensity threshold, $I_{\text {threshold }}$, the difference between the calculated and the measured conductor temperature values is below $1{ }^{\circ} \mathrm{C}$ in the $90 \%$ of the cases and below $2{ }^{\circ} \mathrm{C}$ in the $99 \%$ of the cases. The results are close to the SMT temperature measuring system uncertainty, which is $2 \%$ or $1{ }^{\circ} \mathrm{C}$. It is noticeable that nearly all the selected periods are at night. The long periods with small tension variation are found at night. This could be because at night the wind speed is lower than during the daytime and because the line load is also lower at night.

During the period of two months that the line has been monitored, the creep has not changed and as a consequence the maximum allowable temperature has not varied either. The obtained tension-temperature reference is $750 \mathrm{~kg}$ and $16{ }^{\circ} \mathrm{C}$. This reference gives as a result a conductor maximum allowable temperature of $104^{\circ} \mathrm{C}$.

2) Process of ampacity calculation

As it has been described above, the ampacity calculation is based on the tension monitoring. As an example, the Figure 8 shows the values measured during a whole day.

From the measured tension values and the values of the conductor and span parameters, the TAM System makes an estimate of the conductor temperature. The similarities between the estimated and the measured conductor temperature values are observed in Figure 9. The correlation between the conductor temperature and the ambient temperature is observed too. The mean difference of the absolute value of the difference between the measured and the calculated temperature values is $2{ }^{\circ} \mathrm{C}$. This value depends on the error carried out in the temperature calculation but it also depends on the error of the temperature measurement. Besides, the temperature measurement is local whereas the calculated temperature is representative of the whole span. Furthermore, the measured and calculated temperatures correspond to different phases.

From the estimated conductor temperature and the measured ambient temperature, solar radiation and current intensity, the TAM System estimates the wind speed. The similarities between the estimated and the measured wind speed values are observed in Figure 10. As it has been mentioned above, the measured wind speed values have been modified to correspond to a perpendicular direction. Some of the observed differences are due to the local wind speed variations and the uncertainties of the cup anemometer at low wind values. Besides, there is an error in the calculated wind speed due to the error in the obtained conductor temperature. As it has been mentioned above, the error is lower when the temperature difference is high. The minimum temperature difference occurs at $20: 25$ and it has a value of $7.2{ }^{\circ} \mathrm{C}$. In this case, the measured wind speed is $1.9 \mathrm{~m} / \mathrm{s}$ while the calculated value is $3.8 \mathrm{~m} / \mathrm{s}$. The maximum temperature difference occurs at 10:00 and it has a value of $39.7{ }^{\circ} \mathrm{C}$. In this case, both the measured and calculated wind speed values are the same with a value of $0.3 \mathrm{~m} / \mathrm{s}$.

Once the wind speed is obtained, the ampacity can be calculated. For this purpose, the conductor maximum allowable temperature obtained in the calibration process is necessary. As it has been mentioned before, its value is $104{ }^{\circ} \mathrm{C}$. Figure 11 shows the ampacity evolution. The actual current intensity is also shown and the existing load margin can be observed. There is an error in the calculated ampacity due to the error in the obtained conductor temperature. Assuming that the uncertainty in the conductor temperature value is $2{ }^{\circ} \mathrm{C}$, the ampacity error at $20: 25\left(7.2{ }^{\circ} \mathrm{C}\right.$ temperature difference) is $12 \%$ according to the analysis carried out as a function of the temperature difference error and the temperature difference. The ampacity error at 10:00 $\left(39.7^{\circ} \mathrm{C}\right.$ temperature difference) is $2 \%$. The calculated ampacity value could be corrected reducing the value with the ampacity error. It is important to notice that the ampacity error decreases when the load approaches the limit. When the load is low, although the ampacity error is higher, the margin between the load and the ampacity limit is also higher.

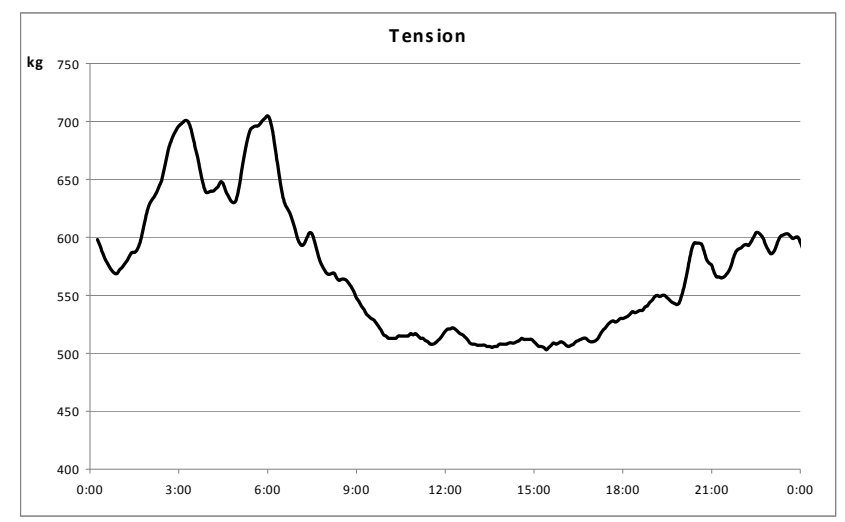

Fig. 8. Tension monitoring during a whole day

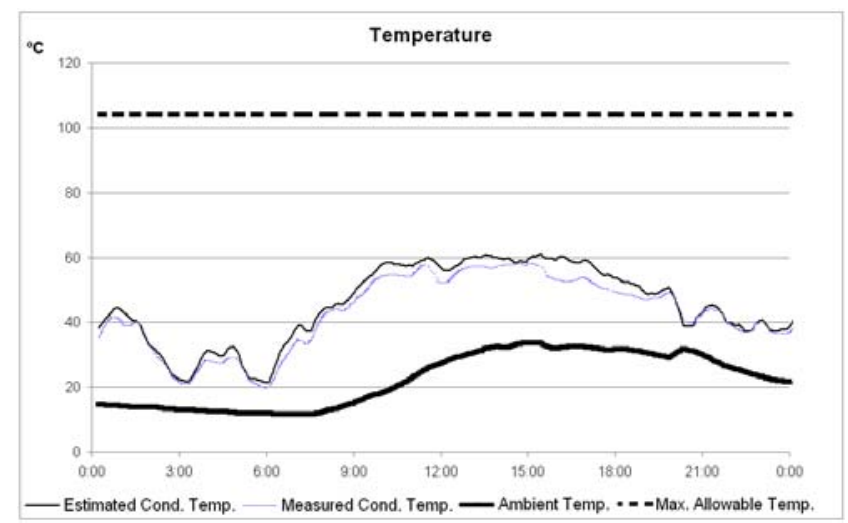

Fig. 9. Verification of the estimated conductor temperature 


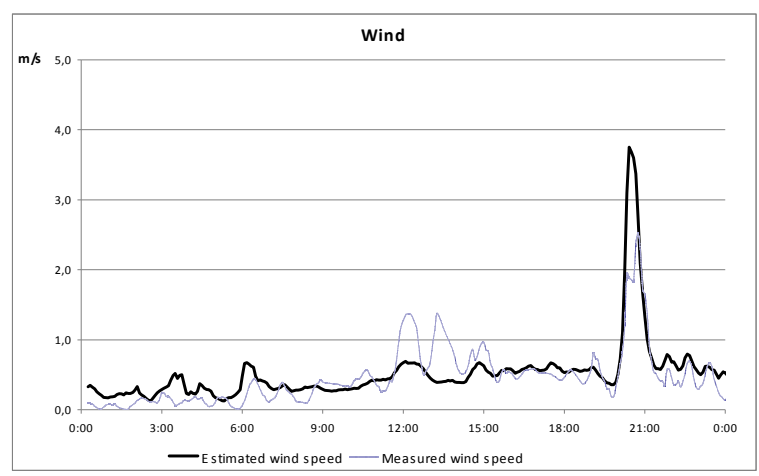

Fig. 10. Wind speed estimate verification.

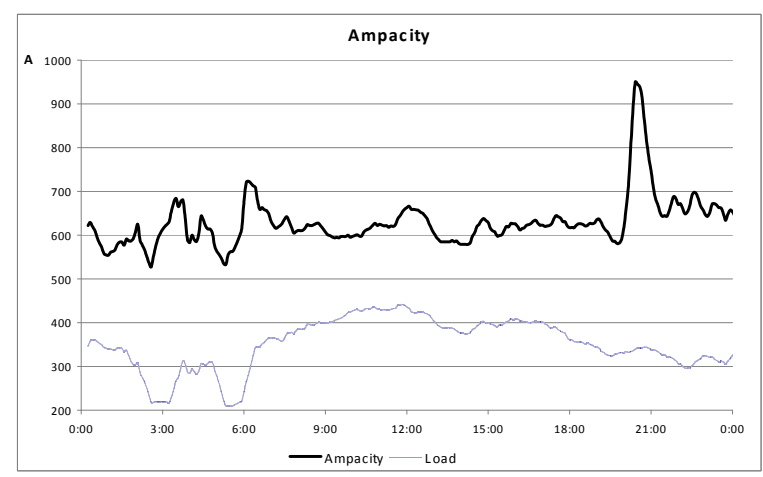

Fig. 11. Ampacity evolution

\section{Benefits}

The main benefits of the TAM System over other monitoring systems are described below.

1) Creep and maximum allowable temperature evaluation

The TAM System evaluates and monitors the evolution of the creep and the maximum allowable temperature. The only system that evaluates the creep is the Power Donut [8]. However, they are different systems because the TAM System is based on tension monitoring while the Power Donut is based on temperature monitoring.

2) Calibration: conductor temperature calculation from ambient temperature, tension, solar radiation and current intensity.

As it has been described above, the TAM System can calculate the conductor temperature with a low error. The calculation is based on the detection of operation conditions with small tension deviation and low current intensity. The system does not measure the wind in order to simplify it and reduce the cost. Hence, the wind speed value is assumed. The results have shown that the method calculates the conductor temperatures with low error values, which are around $1{ }^{\circ} \mathrm{C}$. The method can calculate the conductor temperature only when the conditions are met. Therefore, it is not able to calculate the conductor temperature continuously. However, as the final aim is the calculation of the evolution of the creep and the maximum allowable temperature, the period between two consecutive conductor temperature calculations (usually a few days) is short enough.

3) Simplicity of the measuring elements

The system comprises four measuring elements: tension, ambient temperature, solar radiation and current intensity. There is no need for either wind speed or conductor temperature measurement.

The measuring elements of the TAM System have the advantage that they are installed at ground voltage. Other systems require the installation of elements at line voltage. This is the case of the monitoring systems based on the temperature measuring.

The measuring elements of the TAM System are general purpose elements that are found easily in the market. Other systems have elements that must be especially designed for the monitoring of the ampacity.

\section{CONCLUSIONS}

The monitoring of the sag or the tension gives a direct measurement of the actual sag value, which is usually the magnitude to control. However, in order to obtain the ampacity, weather measurements are also needed. Besides, the tension and the sag monitoring systems require a calibration with respect to the conductor temperature. Once calibrated, the conductor temperature is estimated from the tension or the sag value.

The TAM System, a system that monitors in real time the conductor tension, the ambient temperature, the solar radiation and the current intensity has been presented. The measurements are transmitted via GPRS to a control center where a software program calculates the ampacity value and calibrates the tension-temperature reference. As a result of the calibration process, the creep and the maximum allowable temperature values are updated.

The results obtained in a pilot installation have been presented and analyzed. The method that calculates the conductor temperature for the calibration process has shown to be accurate when the tension deviation and the current intensity values are low. The effect of the conductor temperature calculation error on the ampacity value has been discussed. Although there is an error in the ampacity calculation, this error is low when the load approaches the ampacity limit.

The main benefits of the TAM System over other monitoring systems are the creep evaluation, the developed method for the calculation of the conductor temperature in the calibration and the simplicity of the required measuring elements.

\section{APPENDIX}

\section{A. Sag-tension method}

The algorithm [17] is characterized by the creep sequential calculation. Thus, the creep developed in previous stages influences the creep developed in subsequent stages. Two periods are differenced in the creep development: the installation period and the operation period (Fig. 12). The creep developed during the operation depends on the creep previously developed during the installation. The creep developed during each operation stage is calculated taking into account the creep developed so far.

In each stage, the metallurgical creep $\varepsilon^{\mathrm{mc}}$ and the creep due 
to geometrical settlement $\varepsilon^{\mathrm{gs}}$ are calculated separately. The total creep $\varepsilon^{\text {creep }}$ is the addition of the metallurgical creep $\varepsilon^{\text {mc }}$ and the creep due to geometrical settlement $\varepsilon^{\mathrm{gs}}$. The metallurgical creep is calculated as a function of the conductor tension $T$, the conductor temperature $\theta_{\text {con }}$ and the duration $t$ of the stage. The strain due to geometrical settlement is supposed to be independent of time. It is only dependent on the conductor construction and the historical maximum tension $T^{\max }$ experienced. This calculation process is carried out for the aluminum and the core separately.

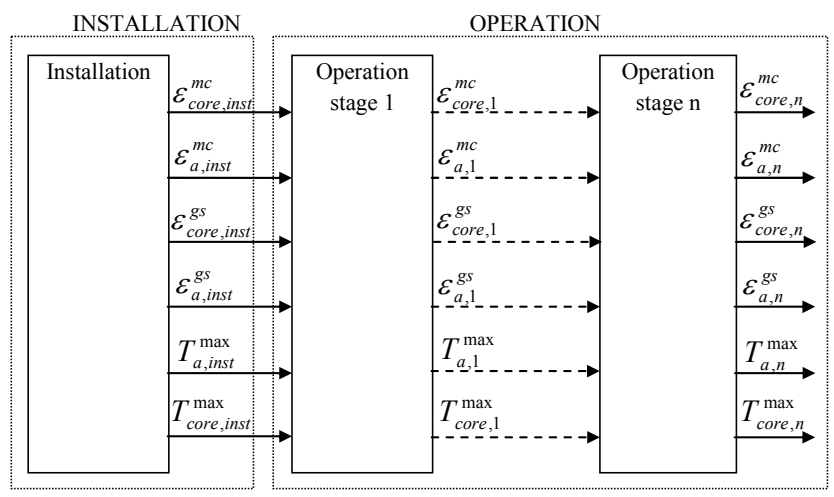

Fig. 12. Creep and maximum tension evolution in time

When the method characterizes the conductor installation it differentiates between the gap-type conductors and the rest of conductors. As it is shown below, in the case of the gap-type conductors the installation steps that affect the aluminum and the core creep are modeled separately. In the case of the non gap-type conductors, the time the conductor is at rest is taken into account and the pretensioning value is taken into account when it is applied.

To calculate the creep developed during the operation, the conductor temperature and the wind and ice loads are assumed to be constant during each operation stage. Thus, the parameters that characterize each stage $i$ are the conductor temperature $\theta_{\text {con, },}$, the load conditions (ice and wind) and the duration $t_{i}$ of the stage.

From the creep strain values calculated for the operation stages, the tension value related to a certain conductor temperature is calculated by the state calculation algorithm. The state calculation algorithm is shown in Figure 13. The core tension $T_{\text {core }}$ is iterated until the difference between the span geometry length $L_{g}$ and the conductor length $L_{c o n}$ is below a threshold value. The aluminum tension $T_{a}$ cannot go below its minimum value. This minimum value is zero or a negative value if aluminum compression is considered.

The state calculation algorithm is based in the dependence of the core and aluminum lengths $L_{c o r e}$ and $L_{a}$ on the strain values due to tension $\varepsilon_{\text {core }}^{T}, \varepsilon_{a}^{T}$, temperature $\varepsilon_{\text {core }}^{\theta}, \varepsilon_{a}^{\theta}$, and creep $\varepsilon_{\text {core }}^{\text {creep }}, \varepsilon_{a}^{\text {creep }}$ and the core and aluminum reference lengths $L_{o}^{\text {core }}$ and $L_{o}^{a}(16,17)$.

The core and aluminum reference lengths $L_{o}^{\text {core }}$ and $L_{o}^{a}$ correspond to the reference condition with no tension and no creep. They are obtained from the installation condition, where the temperature and the tension values are known and the creep strain is estimated from the installation process $(18,19)$. The span geometry is characterized by the catenary equation. The catenary equation is a function of the conductor tension $T$ and the weight $\omega$. The weight value $\omega$ depends on the conductor weight $\omega_{\text {con }}$ and the wind and ice load. The catenary length at the installation $L_{\text {inst }}$ is obtained from the installation tension $T_{\text {inst }}$ and the conductor weight $\omega_{\text {con }}(21)$.

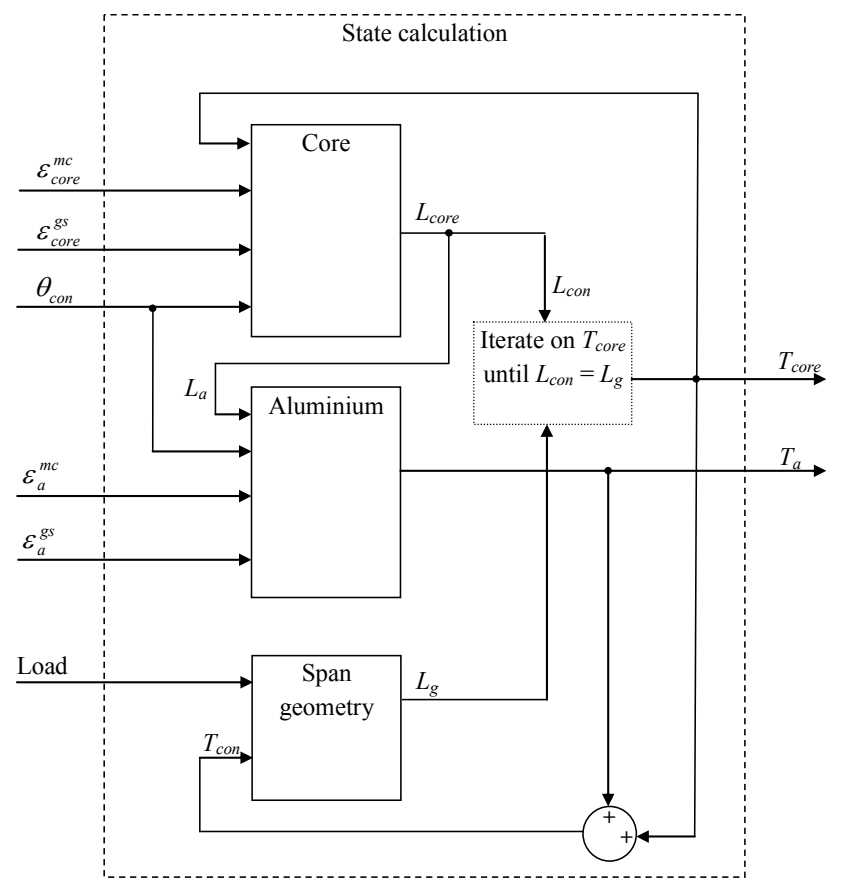

Fig. 13. State calculation algorithm

$L_{a}=L_{o}^{a} \cdot\left(\varepsilon_{a}^{T}+\varepsilon_{a}^{\theta}+\varepsilon_{a}^{\text {creep }}\right)$

$L_{\text {core }}=L_{o}^{\text {core }} \cdot\left(\varepsilon_{\text {core }}^{T}+\varepsilon_{\text {core }}^{\theta}+\varepsilon_{\text {core }}^{\text {cree }}\right)$

$L_{o}^{a}=L_{\text {inst }} /\left(1+\varepsilon_{a, \text { inst }}^{T}+\varepsilon_{a, \text { inst }}^{\theta}+\varepsilon_{a, \text { inst }}^{\text {creep }}\right)$

$L_{o}^{\text {core }}=L_{g} /\left(1+\varepsilon_{\text {core, inst }}^{T}+\varepsilon_{\text {core, inst }}^{\theta}+\varepsilon_{\text {core, } \text {,inst }}^{\text {cree }}\right)$

$c_{\text {inst }}=T_{\text {inst }} / \omega_{\text {con }}$

$L_{\text {inst }}=2 \cdot c_{\text {inst }} \cdot \sinh \left((s / 2) / c_{\text {inst }}\right)$

\section{B. Thermal calculation}

The thermal balance is given by (22), where $P_{j}$ is the Joule heating, $P_{m}$ is the magnetic heating, $P_{s}$ is the solar heating, $P_{c}$ is the convective cooling and $P_{r}$ is the radiative cooling $[3,4]$.

$P_{j}+P_{m}+P_{s}=P_{c}+P_{r}$

\section{1) Current intensity heating}

The current intensity heats a conductor due to several effects. The main heating is due to the Joule effect. The Joule effect is present both in $\mathrm{dc}$ and ac. However, in ac there are other effects that heat the conductor. One of them is the skin effect that results in a non-uniform distribution of the current density that results in an increase of energy losses. Another effect related to ac is the magnetic losses in the conductors with steel core. The current generates an axial magnetic field 
because the wires are stranded helically. The magnetic losses are due to the hysteresis and the Eddy currents.

The energy losses due to the current intensity $I_{a c}$ are represented by the electrical resistance $R_{a c}$ of the conductor. The losses are calculated as the product of the resistance and the square of the current intensity (23). The calculation of the resistance $R_{a c}$ is described in [20].

$P_{j}+P_{m}=I_{a c}^{2} \cdot R_{a c}$

\section{2) Solar heating}

The solar heating is proportional to the conductor diameter $D$, the solar radiation $S$ and the absorptivity of the conductor surface $\alpha$ (24).

$$
P_{s}=\alpha \cdot S \cdot D
$$

\section{3) Convective cooling}

The convective cooling is a function of the wind speed $V$, the angle between the wind direction and the conductor $\delta$, the conductor temperature $\theta$, the ambient temperature $\theta_{\mathrm{a}}$ and the conductor diameter $D$.

\section{4) Radiative cooling}

The radiative cooling value is lower than the convective cooling. It depends on the conductor diameter $\mathrm{D}$, the conductor surface emissivity $\varepsilon$, the conductor surface temperature $\theta$ and the ambient temperature $\theta_{\mathrm{a}}$.

\section{ACKNOWLEDGMENT}

The authors gratefully acknowledge the support of the Iberdrola utility and Saprem and Trefinasa companies for their help with the achievement of this project.

\section{REFERENCES}

[1] R. Stephen, "Description of state of the art methods to determine thermal ratings of lines in real-time and their application in optimising power flow”, CIGRÉ Session, 22-304, Paris-France, 2000.

[2] CIGRÉ 22-12, "Real time monitoring", ELECTRA, No. 197, pp. 35-47, 2001.

[3] "Thermal behaviour of overhead conductors", CIGRÉ 22-12 Brochure (Ref. No. 207), 2002.

[4] IEEE Std 738-2006, "IEEE Standard for Calculating the CurrentTemperature Relationship of Bare Overhead Conductors", 2006.

[5] F. Soto, D. Alvira, L. Martín, J. Latorre, J. Lumbreras, M. Wagensberg, "Increasing the capacity of overhead lines in the $400 \mathrm{kV}$ Spanish transmission network: real time thermal ratings", CIGRE Session, 22211, Paris-France, 1998

[6] H.J. Dräger, D. Hussels, R. Puffer, "Development and implementation of a monitoring-system to increase the capacity of overhead lines", CIGRE Session, B2-101, Paris-France, 2008.

[7] J.S. Engelhardt, S.P. Basu, "Design, installation, and field experience with an overhead transmission dynamic line rating system", IEEE PES Transmission and Distribution Conference, pp. 366-370, Los AngelesUSA, 1996.

[8] J. Engelhardt, "Dynamic lyne rating system with real time tracking of conductor creep to establish the maximum allowable conductor loading as limited by clearance", US Patent 2007/0200556.

[9] "Temperature and current measurement sensor for high voltage lines. SMT", Technical Brochure, Arteche, 2009.

[10] C. Bernauer, H. Böhme, S. Grossmann, V. Hinrichsen, S. Kornhuber, S. Markalous, M. Muhr, T. Strehl, R. Teminova, "Temperature measurement on overhead transmission lines (OHTL) utilizing surface acoustic wave (SAW) sensors", International Conference on Electricity Distribution CIRED, Vienna-Austria, 2007.

[11] T.O. Seppa, H.W. Adams, D.A. Douglass, N. Coad, A. Edris, P. Olivier, F.R. Thrash, "Use of on-line tension monitoring for real-time thermal ratings, ice loads and other environmental effects", CIGRÉ Session, 22102, Paris-France, 1998.

[12] T.O. Seppa, "Increasing transmission capacity by real time monitoring", IEEE PES Winter Meeting, pp. 1208-11, 2002.

[13] B. Forbes, D. Bradshaw, F. Campbell, "Finding hidden capacity in transmission lines", Transmission \& Distribution World, September, 2002.

[14] J.L. Lilien, S. Guérard, J. Destiné, E. Cloet, "Microsystems array for live high voltage lines monitoring", CIGRÉ Session, B2-302, Paris-France, 2006.

[15] I. Albizu, A.J. Mazon, I. Zamora, "Flexible strain-tension calculation method for gap-type overhead conductors", IEEE Transactions on Power Delivery, Vol. 24, No. 3, pp. 1529-1537, 2009.

[16] I. Albizu, A.J. Mazon, V. Valverde, G. Buigues, "Aspects to take into account in the application of mechanical calculation to high temperature low sag conductors", IET Generation Transmission \& Distribution, Vol. 4, No. 5, pp. 631-640, 2010.

[17] I. Albizu, A.J. Mazon, E. Fernandez, "A method for the sag-tension calculation in electrical overhead lines", International Review of Electrical Engineering (IREE), Vol. 6, No. 3, pp. 1380-1389, 2011.

[18] I. Albizu, E. Fernandez, A.J. Mazon, J. Bengoechea, "Influence of the conductor temperature error on the overhead line ampacity monitoring systems", IET Generation Transmission \& Distribution, Vol. 5, No. 4, pp. 440-447, 2011.

[19] M. Landeira, P. Morentin, A.J. Mazon, I. Albizu, "The high temperature cable solution for electrical overhead distribution lines", DYNA, Vol. 82, No. 5, pp. 226-230, 2007.

[20] "Alternating current (ac) resistance of helically stranded conductors", CIGRÉ B2-12 Brochure (Ref. No. 345), 2008.

\section{BIOGRAPHIES}

Igor Albizu was born in Zumaia, Spain, in 1975. He received the M.Sc. degree in electronic instrumentations systems from UMIST, Manchester, U.K., in 1999, and the Ph.D. degree from the University of the Basque Country, Bilbao, Spain, in 2008.

Currently, he is a Lecturer with the University of the Basque Country. His research activities are concentrated in the area of transmission-line thermal rating.

Elvira Fernández was born in Bilbao, Spain, in 1973. She received her Ph.D. degree in Electrical Engineering from the University of the Basque Country, Bilbao, Spain, in 2008.

Currently, she is a Lecturer with University of the Basque Country. Her research activities are concentrated in the area of transmission-line thermal rating.

Pablo Eguía (M’09) was born in Bilbao, Spain, in 1973. He received his $\mathrm{Ph} . \mathrm{D}$. degree in Electrical Engineering from the University of the Basque Country, Bilbao, Spain, in 2007.

Currently, he is a Lecturer with the University of the Basque Country. His research activities include power systems analysis and simulation, integration of distributed generation and power system protection.

Esther Torres was born in Bilbao, Spain, in 1972. She received her $\mathrm{Ph} . \mathrm{D}$. degree in Electrical Engineering from the University of the Basque Country, Bilbao, Spain, in 2008

Currently, she is a Lecturer with the University of the Basque Country. Her research interests are in the area of power systems analysis and simulation, electric deregulation, and transmission and distribution planning.

Angel Javier Mazón (M’03) was born in Bilbao, Spain, in 1965. He received the Ph.D. degree from the University of the Basque Country, Bilbao, Spain, in 1994. In 1992, he was with Labein Research Laboratories.

Currently, he is a Full-Time Professor with the University of the Basque Country. His research activities are concentrated in the area of electric power systems, fault analysis, and transmission-line thermal rating. 